\title{
La Virgen y el Niño en la huida a Egipto de Paul Coecke van Aelst
}

\author{
The Virgin and Child in Flight into Egypt by Paul Coecke van Aelst
}

\begin{abstract}
Matías Díaz Padrón ${ }^{1}$
Académie Royale d'Archéologie et d'Histoire de l'Art de Belgique Instituto Moll. Centro de investigación de pintura flamenca
\end{abstract}

Resumen: En este artículo se estudia e identifica un original de La Virgen y el Niño en la huida a Egipto, tradicionalmente atribuido a Pieter Coecke van Aelst, como obra de su hijo Paul Coecke van Aelst, quien solía copiar pinturas de Jan Gossaert incluyendo algunos detalles personales.

Palabras clave: Paul Coecke van Aelst; Pieter Coecke van Aelst; Jan Gossaert; Flandes; Amberes; siglo XVI; pintura.

Abstract: Abstract: This paper studies an original work, The Virgin and Child in Flight into Egypt, usually attributed to Pieter Coecke van Aelst, and identify as a work by his son Paul Coecke van Aelst, who would copy paintings by Jan Gossaert and personalize them by adding details of his own.

Keywords: Paul Coecke van Aelst; Pieter Coecke van Aelst; Jan Gossaert; Flanders; Antwerp; $16^{\text {th }}$ century; Painting.

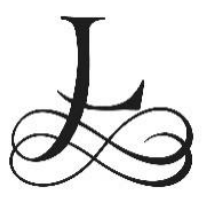

a Virgen se despoja de la frontal solemnidad para dejarse ver como madre con su hijo en el regazo, bajo el fondo de una fértil campiña con montañas en la lejanía. El pintor capta un instante en que el Niño inquieto retira el velo que le impide ver al previsto espectador. Un instante novedoso y vivo. La Virgen es consciente de estar siendo mirada. La disposición frontal no vela el ensimismamiento de su espíritu. El Niño no está dormido, ni triste por su previsible futuro. Tal como es habitual en la huida a Egipto, la secuencia

1 @https://orcid.org/0000-0002-5137-7583

(C) 2020 Philostrato. Revista de Historia y Arte 
anterior la marca en la lejanía la marcha sobre el burro de la Virgen y el Niño con san José a pie. La Virgen ha hecho una parada en la huida. Descansa en una rica mansión. El pintor se entretiene en narrar a lo lejos la vida de los campesinos en sus faenas cotidianas. La arquitectura es la propia de un rico palacio con pilastras y entablamentos rotos, en las tierras fértiles de Flandes ${ }^{2}$ (Fig. 1).

La tabla que tratamos es pieza de gran calidad. Una de las mejores que han llegado a nosotros por su exquisita ejecución. Muy cuidada y primorosa en los detalles, como en la técnica del sólido soporte y la exquisita conservación de los colores. Esto al paso de los siglos que median entre la pintura y nosotros. Una valoración de la técnica que a veces se olvida por la inevitable seducción de la estética. Conserva un marco de calidad cuya inscripción delata una procedencia inmediata en el ámbito hispano que no es extraña a la producción conocida de Paul Coecke ${ }^{3}$. Un escudo de armas laureado se aprecia en la parte inferior izquierda de la pintura, sin identificar los motivos de los cuarteles.

En primer término y sobre el friso del muro, se dispersan distintas frutas de claro sentido simbólico alusivo a las virtudes de la Virgen. Frutas del Paraíso: las cerezas son premio a la virtud y símbolo del cielo; la manzana alude a la misión redentora de Jesús; la pera a la encarnación de Cristo y su amor a la humanidad; en un rico jarrón de bronce con relieves y doble asa, los lirios son signo de la pureza de María 4 .

Adelanto la autoría de esta tabla a Paul Coecke, frente a la tradicional atribución a Pieter Coecke, el más conocido de este nombre en el siglo XVI y con abundante producción en España ${ }^{5}$. Pieter Coecke fue pintor del emperador Carlos $V$ con vínculos al poderío de España ${ }^{6}$. No podemos evitar el recuerdo de su intervención en los arcos de triunfo a la entrada en Amberes del príncipe Felipe ${ }^{7}$. Nada extraña la confusión de la obra de Paul Coecke con la de Pieter Coecke. Esto es muy frecuente.

La atribución tradicional a Pieter Coecke es normal y reiterada en sus pinturas. Es en estos últimos años cuando se ha reconocido la notable calidad de la obra de Paul Coecke y la distancia con la de su padre, Pieter Coecke. Debemos los estudios de la personalidad y producción de Paul Coecke a Aida Padrón en 1985 y $1988^{\circ}$. Reúne un buen número de piezas en España y en el extranjero, con análisis de su estilo y diferencia al de su

\footnotetext{
2 Tabla, $127 \times 104 \mathrm{~cm}$.

3 "A 10 DE OCTUBRE DE 1601 EN LAS FIESTAS DE / LA REINA HIZO LA VIRGEN DEL REMIDIO ESTE/ MILAGRO EN FRANZISCO MANUEL ROMAN / EN SU MUGER MARIA DEL [...]".

${ }^{4}$ George Ferguson, Signs \& Symbols in Christian Art, (New York: Oxford University Press, 1966), pp. 41 y 46; James Hall, Dizionario dei soggetti e dei simboli nell'arte, (Milano: Longanesi, 1974), pp. 12 y 226.

${ }^{5}$ George Marlier, La renaissance flamande. Pierre Coeck d'Alost, (Brussels: Robert Finck, 1966), p. 36.

${ }^{6}$ Marlier, Renaissance flamande..., pp. 39, 42-43.

7 Marlier, Renaissance flamande..., p. 43.

8 Aida Padrón Mérida, "Paul Coeck y la Virgen y Niño con velo", Boletín del Museo e Instituto Camón Aznar, XX, (1985), pp. 137-150; Aida Padrón Mérida, "Un tríptico inédito y algunas tablas de Virgen y Niño con velo por Paul Coeck", Boletín del Instituto Camón Aznar, XXXIII, (1988) pp. 5-16.
} 


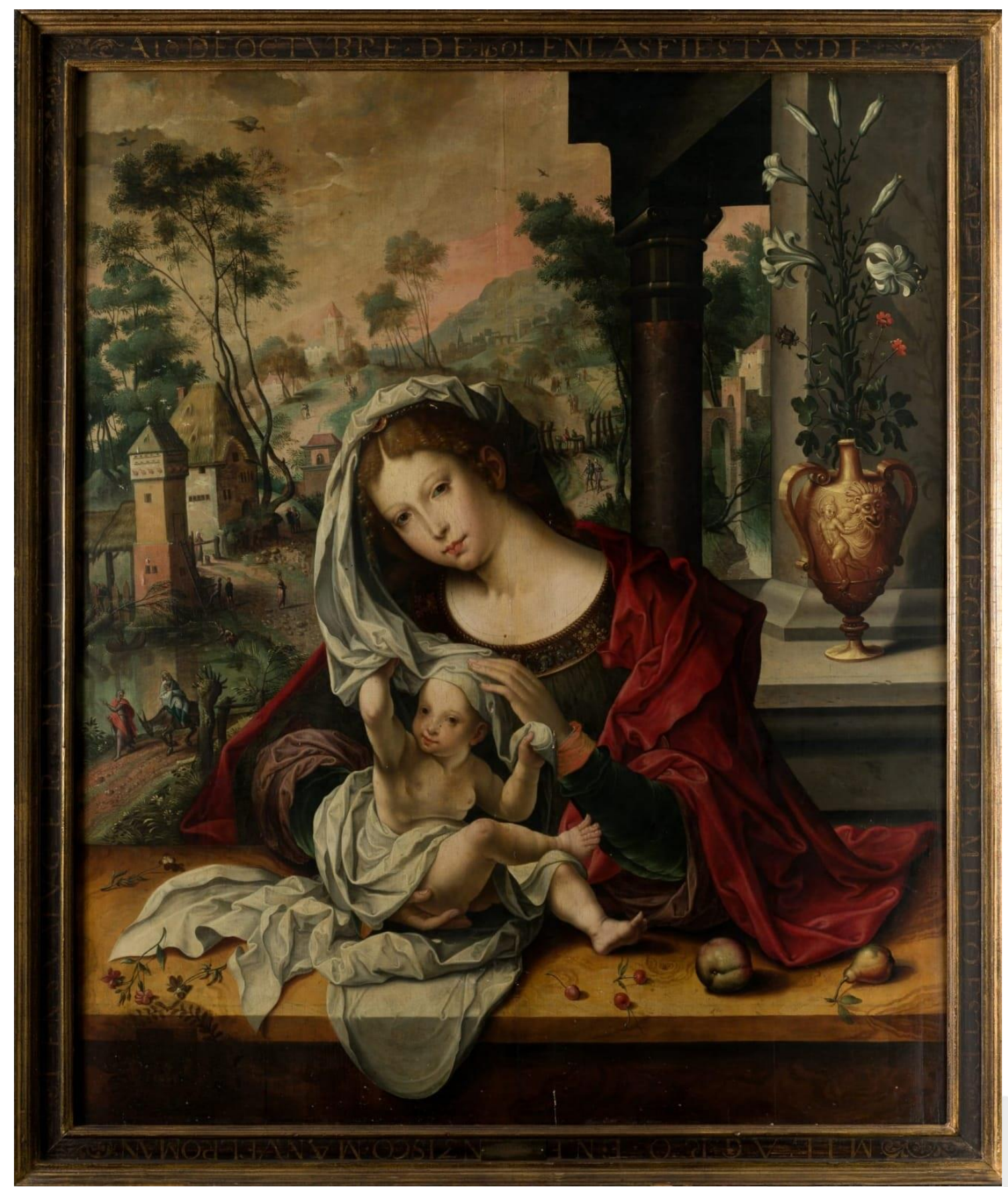

Fig. 1. Paul Coeck van Aelst, La Virgen y el Niño en la huida a Egipto, colección privada. @Fotografia: autor

padre. A ello cabe añadir un nuevo original en el coleccionismo privado de Méjico, estudiado por quien esto escribe ${ }^{9}$.

9 Matías Díaz Padrón, "Tres pinturas flamencas identificadas en Méjico", BSAA arte, LXXI, (2005), pp. 163-173. 


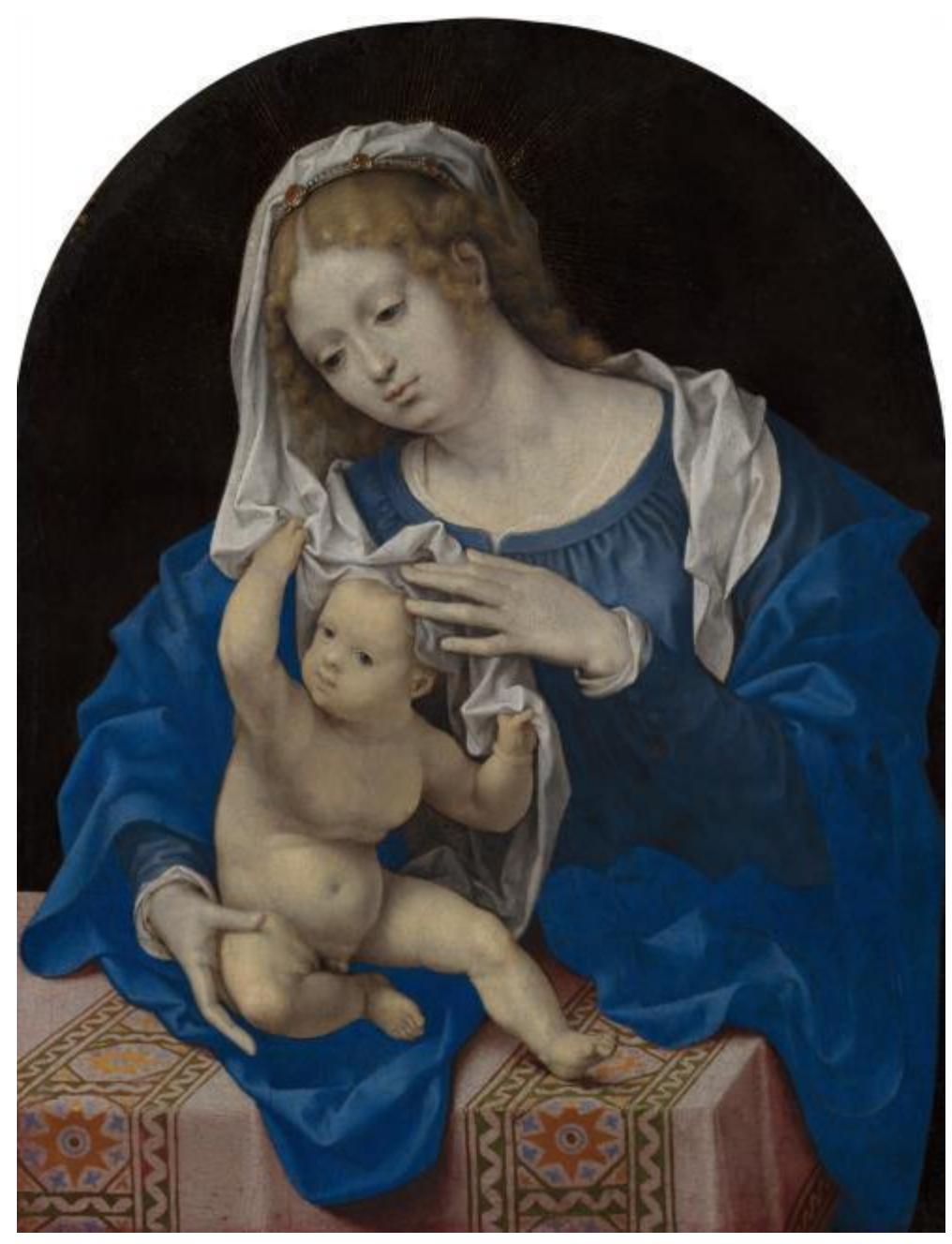

Fig. 2. Jan Gossart, La Virgen con el Niño, La Haya, Koninklijk Kabinet van Schilderijen Mauritshuis (inv. $\mathrm{n}^{\circ} 830$ ) CFotografía: Maurithuis

Paul Coecke es hijo natural de Pierre Coecke y de Antoinette van der Sant. Nace en 1530, probablemente en Amberes ${ }^{10}$. Conocemos noticias muy directas por Carel Van Mander. Este biógrafo tan próximo nos comenta de la imitación de modelos de Jan Gossaert, conocido como Mabuse, con reconocimiento de su talento: "Paul van Aelst, hijo bastardo de Pierre Coecke, ha copiado con un talento particular las obras de Jan Mabuse, y pintó también pequeños vasos con flores muy limpios y puros. Vivió y murió en Amberes"11. Escueto comentario muy acorde con las pinturas que conocemos. La atención al valorar las pinturas de jarrones se confirma en la tabla de tan exquisito esmero que estudiamos. Es evidente que fueron obje-

${ }^{10}$ Frans Jozef Peter van den Branden, Geschiedenis der Antwerpsche schilderschool, (Antwerpen: 1883), p. 151 , nota 3.

11 "Pauwels van Aelst, fils bâtard de Pieter Koeck était excellent dans la copie des choses de Joan Mabuse, et il exécutait aussi de façon très nette et pure des petits verres avec des fleurs. Il habitait et mourut à Anvers". Carel van Mander, Le Livre des peintres, ed. Henry Hymans, I, (Paris: J. Rouan, 1884 [Haarlem, 1603-1604]), p. 188. 


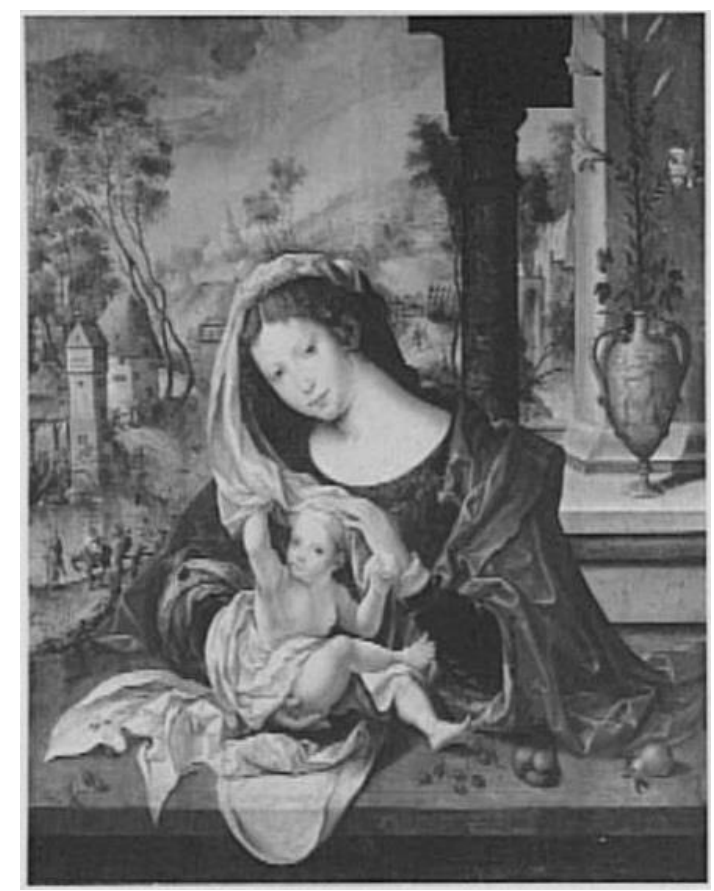

Fig. 3. Paul Coecke, La Virgen y el Niño en la huida a Egipto, Bruselas, Musées royaux des Beaux-Arts de Belgique (inv. $n^{\circ}$ 587) CFotografía: KIKIRPA

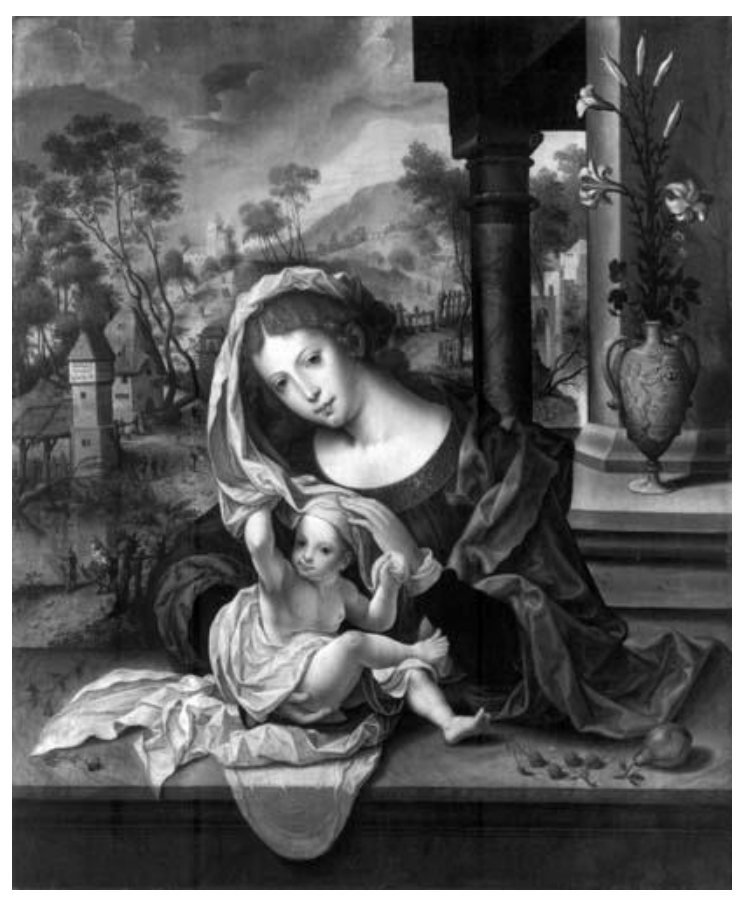

Fig. 5. Paul Coecke, La Virgen y el Niño en la Huida a Egipto, Ámsterdam, colección privada. OFotografía: KIKIRPA

to de atención y éxito, a la vista del que vemos junto a la Virgen en esta tabla que tratamos. La fecha de su muerte en 1569, fijada por Duverger, es muy útil para establecer los años que abarcan su producción ${ }^{12}$.

La factura es más modulada y uniforme que la cerrada y lineal en Pieter Coecke. Pero a todo esto, tanto en la tabla que estudiamos como en las réplicas, es evidente la fuente directa de Jan Gossaert, cuyo original está en el Mauritshuis de La Haya (inv. 830) ${ }^{13}$ (Fig. 2). Las diferencias con Jan Gossaert están en el fondo uniforme y oscuro, y en la Virgen que contempla al Niño con profunda ternura, mientras que Paul Coecke vuelve la mirada de la Virgen al espectador. El Niño está desnudo en la pintura de Gossaert, y más recatado, con el velo envolviendo su cuerpo y la pierna derecha cruzada sobre la izquierda, en Paul Coecke. La mano de la Virgen se diseña frontal en Gossaert, mientras que Paul Coecke la gira en perspectiva. El rostro de la Virgen es más redondo en Gossaert, y ligeramente más alargado en Paul Coecke. Escasas diferencias que Paul Coecke sigue en todas las repeticiones que llegan a nosotros. La mirada es más concentrada

12 Erik Duverger, "Enkele gegevens over de Antwerpse schilder Pauwels Coecke van Aelst (†1569), zoon van Pieter en Anthonet van Sant", Jaarboek Koninklijk Museum voor Schone Kunsten, Antwerpen, (1979) pp. 211-226; Erik Duverger, "Coecke van Aelst, Pauwels schilder", en Nationaal biografisch woordenboek, IX, (Bruxelles: Koninklijke Academiën van België / Paleis der Academiën, 1981), pp. 155160; Cit. Padrón Mérida, "Un tríptico inédito y algunas tablas de Virgen y Niño con velo por Paul Coeck", Boletín del Instituto Camón Aznar, XXXIII, (1988), p. 5, nota 2.

${ }^{13}$ (Tabla, 25,4 x 19,3 cm). Koninklijk Kabinet van Schilderijen Mauritshuis, The Hague (inv. 830). 


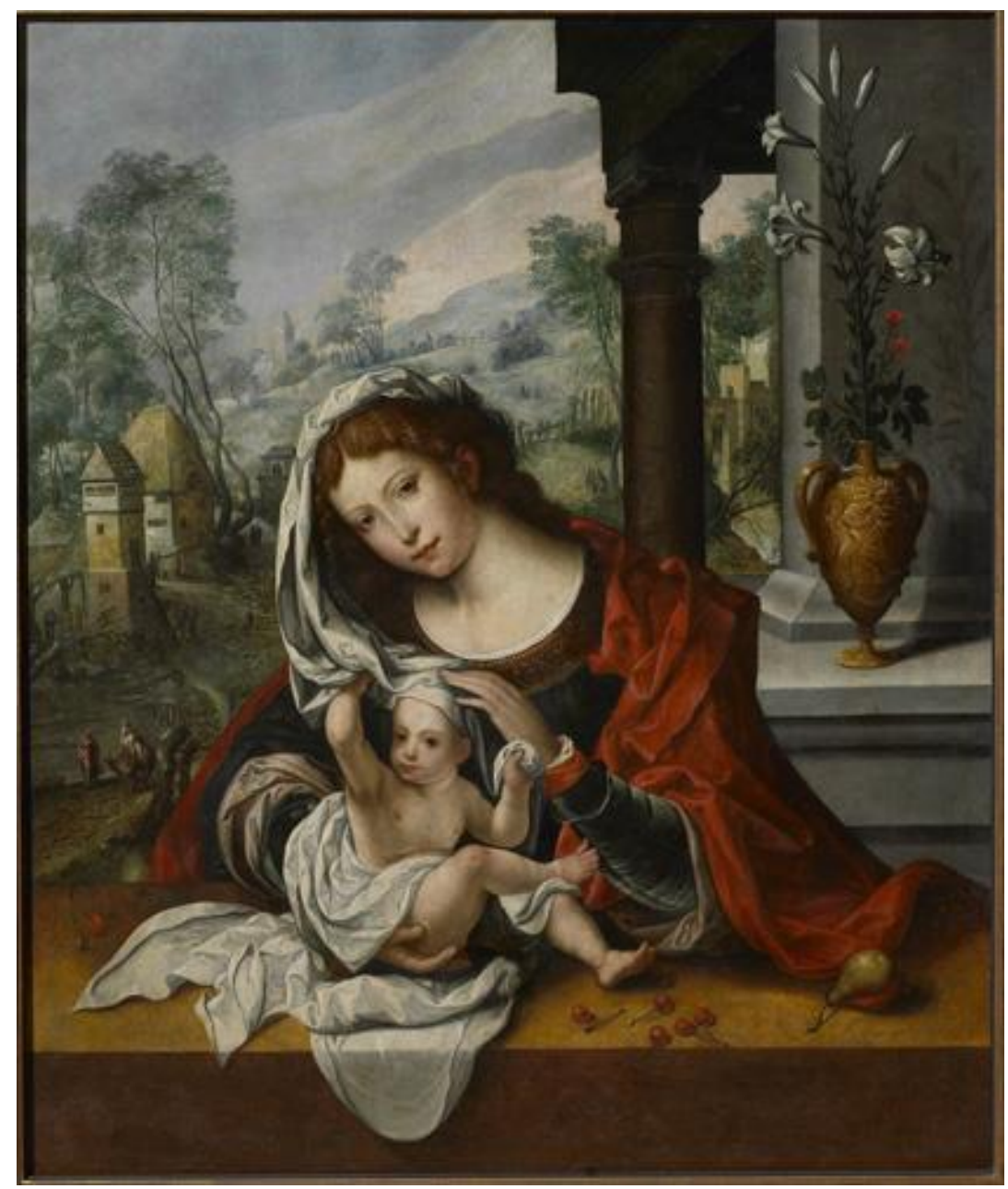

Fig. 4. Paul Coecke, La Virgen y el Niño en la huida a Egipto, Douai, Musée de la Chartreuse (inv. $\mathrm{n}^{\circ}$ 283) (CFotografía: Musée de la Chartreuse

en Gossaert y el rico tapiz sobre el alfeizar de piedra lo retira Paul Coecke para dejar sitio a las frutas con los símbolos aludidos.

La riqueza del paisaje panorámico es una aportación de Paul Coecke. Un bosque y un cielo azul con montañas y la Virgen frente a la balaustrada. La rica composición de esta tabla la repite con exactitud en más ocasiones con evidente esmero. Cuatro réplicas hemos podido localizar: en el museo de Bellas Artes de Bruselas (inv. 587) como obra de Gossaert ${ }^{14}$ (Fig. 3); en el comercio de Nueva York en 1994, también adscrita al círculo de Jan Gossaert ${ }^{15}$; en el museo de la Cartuja de Douai (inv. 283) como obra de Go-

14 (Tabla, $127 \times 104 \mathrm{~cm}$ ). Bruselas, Musée Royaux des Beaux Arts (inv. 587). Procede de la iglesia de Perwez, Nivelles, 1846. Marlier, Renaissance flamande, p. 245; Liesbeth De Belie en Eliane de Wilde et al., Le Musée Caché: À la découverte des réserves/ Het Verborgen Museum: ontdekkingstocht in de reserves, (Bruxelles / Brussel: Koninklijke Musea voor Schone Kunsten van België / Musée royaux des Beaux-Arts de Belgique, 1994), p. 25, n.0 5.

15 (Tabla, $127 \times$ 104,8 cm). Nueva York, Christie's, (12-I-1994, no 237). Procede del Dr. Warre, Sotheby's, Londres, (3/4-VI-1913, no 127), como Mabuse; adquirida en Londres en 1942 por José Joaquín de Lima y Silvia Moniz de Aragón, Embajador de Brasil en la corte de St. James 1942-1952; expuesto en Londres, Royal Academy, Winter Exhibition, 1907, nº 2. 


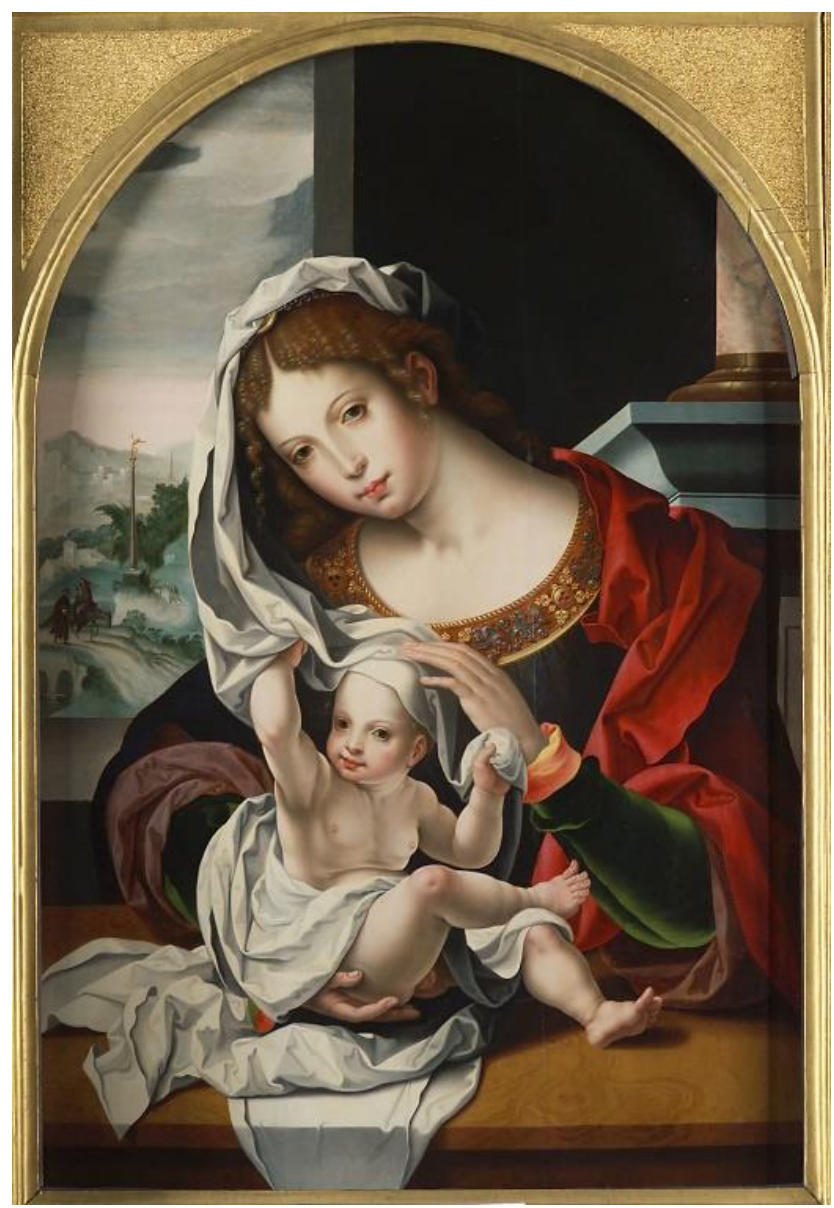

Fig. 6. Paul Coecke, La Virgen con el Niño, Viena, Kunsthistorisches Museum (inv. 2048) OFotografía: Kunsthistorisches Museum, Wien

ssaert $^{16}$ (Fig. 4); otra más aparece en el comercio del arte en Ámsterdam, procedente de la colección Goekoop-De Jong ${ }^{17}$ (Fig. 5). La de colección madrileña que estudiamos figuraba con autoría equivocada y sin noticias de su origen. Ha sido posible asociarla con la que registra en el siglo XIX la colección de Julien Gréau en París en 1830 y en el comercio del arte de F. Kleinberger en París y en Nueva York en 1934.

Las cuatro tablas son prácticamente idénticas en composición y detalles. La Virgen está de medio cuerpo y al fondo un paisaje con arbolado y el cielo azul. La Virgen, como ya se adelantó, está frente a una balaustrada de piedra y al lado de una rica pilastra. En todas, el zócalo está cubierto de flores y frutas donde el pintor se ha permitido alguna diferencia en la disposición y naturaleza de las mismas. Es preciso prestar atención para ver

16 (Tabla, $126 \times 106 \mathrm{~cm}$ ). Douai, Musée de La Chartreuse (inv. 283); Trésors anciens et nouveaux de Wallonie: ce curieux pays curieux, Cat. Exp., Bruxelles, Palais des beaux-arts, 14 février-18 mai 2008, (Bruxelles: Bozar books; 2008), p. 67 (agradezco a la Dra. Ana Diéguez-Rodríguez la localización de esta réplica).

17 (Tabla, 121,5 x 103,2 cm). Amsterdam, Christie's (7-V-1996, no 23). Procede de las colecciones Goekoop-De Jong, Breda/Wassenaar y J. van der Kellen, de Rotterdam. 


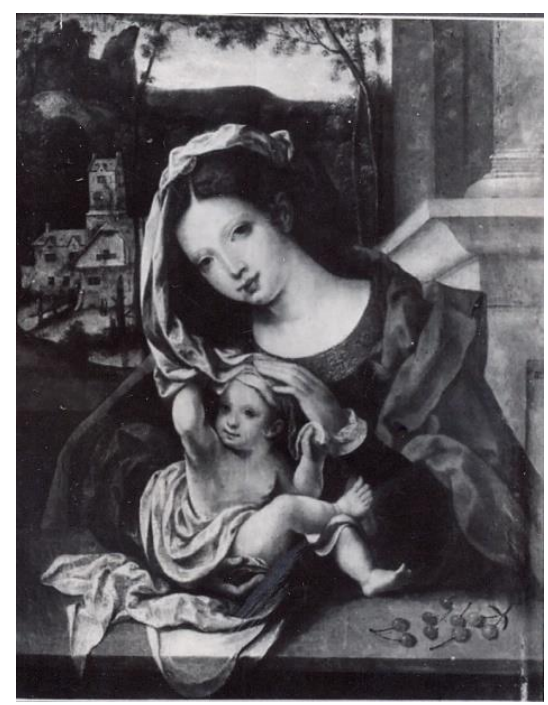

Fig. 7. Paul Coecke, La Virgen con el Niño, Sevilla, Ayuntamiento, en depósito en el museo de Bellas Artes de Sevilla. CFotografía: Museo de Bellas Artes de Sevilla

las mínimas diferencias entre estas excelentes pinturas. Las frutas, como se ha dicho, son alusivas al mensaje sacro. El fondo de bosque y cielo lo vemos más limpio y lejano en la versión que estudiamos, con menor altura en las montañas y más reducido arbolado. Es exquisito el frescor de los colores contrastando la túnica roja y el manto azul cargados de la ideología conocida. La pétrea arquitectura contrasta con las carnaciones y las telas pesadas y ligeras de la Virgen y el Niño. La Virgen nos mira de frente, a diferencia del modelo de Gossaert ensimismada en el presagio doloroso de la muerte. La gracia del ritmo envolvente del velo ha sido, sin duda, motivo de la fama y éxito de esta composición.

Este modelo va a repetirlo Paul Coecke simplificado en numerosas versiones con escasas variantes. La del museo de Bellas artes de Bruselas (inv. 673) con un brocado y abriendo un pequeño vano a la izquierda ${ }^{18}$, simplifica la arquitectura y el paisaje en las versiones del Kunsthistorisches de Viena (inv. 2048) ${ }^{19}$ (Fig. 6), ayuntamiento de Sevilla20 (Fig. 7), galería Robert Finck de Bruselas ${ }^{21}$, colección Sedelmayer de Paris ${ }^{22}$, Petit Palais de París $^{23}$, Museum für Stadtgeschiechte en Dessau-Rossalu ${ }^{24}$ y colección

18 (Tabla, 59 x 46,5 cm). Henry Pauwels et al. Musées royaux des Beaux-Arts de Belgique, Départament d'Art Ancien, Catalogue inventaire de la peinture ancienne, (Bruxelles: Musées Royaux des Beaux-Arts de Belgique, 1984), p. 123, n. ${ }^{0} 673$.

19 (Tabla, 109 x $70 \mathrm{~cm}$ ). (En web: www.khm.at/de/object/b0b183c207/, consultada: 18 de agosto de 2020). Padrón Mérida, "Paul Coeck y la Virgen...", p. 139.

${ }^{20}$ (Tabla $69 \times 53 \mathrm{~cm}$ ). En depósito temporal en el Museo de Bellas Artes de Sevilla. Padrón Mérida, "Paul Coeck y la Virgen ..., p. 138; Padrón Mérida, "Un tríptico inédito...", p. 7.

${ }^{21}$ Marlier atribuye dos tablas de La Virgen y el Niño en ventas de la galería Robert Finck de Bruselas, una en diciembre de 1961 (T. $95 \times 78 \mathrm{~cm}$ ) y la segunda el 16 de diciembre de 1962, n. ${ }^{\circ} 10$ (T. $77 \times 58$ $\mathrm{cm}$ ) de diciembre de 1961 y 1962. Marlier, Renaissance flamande, p. 245, cit. Padrón Mérida, "Paul Coeck y la Virgen", pp. 137 y 139. Otra más en la galería Robert Finck en 1974 atribuyó a Paul Coeck Padrón Mérida, "Paul Coeck y la Virgen", pp. 139-140.

22 (Tabla, 66 × $52 \mathrm{~cm}$ ). Padrón Mérida, "Paul Coeck y la Virgen", p. 140.

23 (Tabla, $85 \times 63 \mathrm{~cm}$ ). Padrón Mérida, "Un tríptico inédito", p. 8.

24 (Tabla, 61,8 x 45 cm). Padrón Mérida, "Un tríptico inédito", p. 7. 
Alfred Gerasch en Viena ${ }^{25}$. En todas, el velo juega el principal papel: simpático y original. De aquí parte su mayor éxito. Los estudiosos han visto en esto un toque de encanto íntimo y familiar.

Es merecido insistir en la estimación de lo dicho por Van Mander, marcando la distancia con la obra de su padre. Es de esperar, por lo que vamos investigando, que en el futuro salgan a la luz muchas más obras de su mano.

25 (Tabla, $89 \times 70 \mathrm{~cm}$ ). Atribuida a Paul Coecke por Marlier, Renaissance flamande, p. 245. 
Bibliografía:

Branden 1883: Frans Jozef Peter van den Branden, Geschiedenis der Antwerpsche schilderschool, (Antwerpen: 1883).

Bruselas 2008: Trésors anciens et nouveaux de Wallonie: ce curieux pays curieux, Cat. Exp., Bruxelles, Palais des beaux-arts, 14 février-18 mai 2008., (Bruxelles: Bozar books; 2008).

De Belie \& De Wilde 1994: Liesbeth De Belie en Eliane de Wilde et al., Le Musée Caché: À la découverte des réserves/ Het Verborgen Museum: ontdekkingstocht in de reserves, (Bruxelles / Brussel: Koninklijke Musea voor Schone Kunsten van België / Musée royaux des Beaux-Arts de Belgique: 1994).

Díaz Padrón 2005: Matías Díaz Padrón, "Tres pinturas flamencas identificadas en Méjico", BSAA arte, LXXI, (2005) pp. 163-173.

Duverger 1979: Erik Duverger, "Enkele gegevens over de Antwerpse schilder Pauwels Coecke van Aelst (†1596), zoon van Pieter en Anthonet van Sant" Jaarboek Koninklijk Museum voor Schone Kunsten Antwerpen, (1979), pp. 211-226.

Duverger 1981: Erik Duverger, "Coecke van Aelst, Pauwels schiler" en Nationaal biografisch woordenboek, IX, (Bruxelles: Koninklijke Academiën van België / Paleis der Academiën, 1981), pp. 155-160.

Ferguson 1966: George Ferguson, Signs \& Symbols in Christian Art, (New York: Oxford University Press, 1966).

Hall 1974: James Hall, Dizionario dei soggetti e dei simboli nell'arte, (Milano: Longanesi, 1974).

Marlier 1966: Marlier, La renaissance flamande: Pierre Coeck d'Alost, (Brussels: Robert Finck, 1966).

Padrón Mérida 1985: Aida Padrón Mérida, "Paul Coeck y la Virgen y Niño con velo", Boletín del Museo e Instituto Camón Aznar, XX, (1985), pp. 137150.

Padrón Mérida 1988: Aida Padrón Mérida, "Un tríptico inédito y algunas tablas de Virgen y Niño con velo por Paul Coeck", Boletín del Instituto Camón Aznar, XXXIII, (1988), pp. 5-16.

Pauwels et al. 1984: Henry Pauwels et al. Musées royaux des Beaux-Arts de Belgique, Départament d'Art Ancien, Catalogue inventaire de la peinture ancienne, (Bruxelles: Musées royaux des Beaux-Arts de Belgique, 1984). 
Van Mander 1884 (1603-1604), ed. Hymans 1884: Carel van Mander, Le Livre des peintres, ed. Henry Hymans, I, (Paris: J. Rouan, 1884 [Haarlem, 1603-1604]).

Recibido: 09/09/2020

Aceptado: $28 / 10 / 2020$ 